\title{
Trajetórias de homens em busca do cuidado em saúde: desafios para a atenção primária em um contexto rural
}

\author{
Maria Deysiane Porto Araújo \\ Médica. Mestra em Saúde da Família (FIOCRUZ). Professora do Curso de \\ Medicina da Universidade Federal de Alagoas, Campus Arapiraca \\ \maria.araujo@arapiraca.ufal.br \\ Angélica Ferreira Fonseca \\ Sanitarista. Doutora em Saúde Pública (FIOCRUZ). Professora e pesquisadora da \\ Escola Politécnica de Saúde Joaquim Venâncio da Fundação Oswaldo Cruz \\ $\square$ angelica.fonseca@fiocruz.br \\ Michael Ferreira Machado \\ Sanitarista. Doutor pela Universidade Federal de Pernambuco. Professor do \\ Curso de Medicina da Universidade Federal de Alagoas, Campus Arapiraca \\ \michael.machado@arapiraca.ufal.br \\ Túlio Romério Lopes Quirino \\ Psicólogo. Doutor em Psicologia pela Universidade Federal de Pernambuco \\ Professor da Universidade de Pernambuco, Campus Mata Norte \\ $\triangle$ tulio.quirino@recife.pe.gov.br
}

\section{Resumo:}

Estudo qualitativo exploratório com objetivo de compreender o percurso de homens em busca do cuidado em saúde. Participaram da pesquisa 20 homens, entre 20 a 59 anos, residentes do povoado Laranjal, comunidade rural do município de Arapiraca-AL. Dentre estes, 10 homens utilizaram o serviço de atenção primária à saúde nos últimos doze meses anteriores a coleta dos dados e os outros 10 não fizeram uso desse serviço neste período. Foi utilizada a entrevista semiestruturada como estratégia metodológica para construção das informações. Para análise dos dados, utilizou-se como arcabouço teórico-analítico, a análise de enunciação. A partir da discussão dos resultados, aponta-se que os homens participantes do estudo não têm trajetórias (itinerários) bem definidas, talvez tracejados, linhas frágeis para a condução de si mesmos que se esboçam, à medida que situações críticas de adoecimento surgem; recorrem com frequência a automedicação e/outras soluções caseiras frente a um problema de saúde; só buscam cuidados profissionais, seja a unidade Básica de Saúde ou o hospital quando identificam o agravamento de sintomas. A ideia de prevenção e/ou estratégias de autocuidado estão quase ausente das falas. Nesta direção, destacamos a importância de se analisar as singularidades da população masculina de cada região, reconhecendo a realidade dos serviços disponíveis em cada contexto, os recursos disponíveis para o cuidado em saúde, bem como a necessidade de qualificação dos profissionais de saúde para serem estabelecidas estratégias voltadas à inclusão do público masculino no cenário da saúde, sendo importante a superação do modelo assistencial-curativista, fortemente presente na rede de saúde.

Palavras-chave: Saúde do homem, Atenção primária à saúde, Masculinidade, Atenção à saúde. 


\title{
Trajectories of men seeking health care: challenges for primary care in a rural context
}

\begin{abstract}
:
Qualitative exploratory study with the objective of understanding the path of men in search of health care. Twenty men, between 20 and 59 years of age, residents of Laranjal village, a rural community in the municipality of Arapiraca-AL, participated in the survey. Among these, 10 men had used the primary health care service in the last 12 months and the other 10 had not used this service in this period. The semi-structured interview was used as a methodological strategy for building the information. For data analysis, enunciation analysis was used as theoretical and analytical framework. From the discussion of the results, it is pointed out that the men participating in the study do not have well-defined trajectories (itineraries), perhaps dashed, fragile lines for the conduction of themselves that are outlined as critical situations of illness arise; they frequently resort to selfmedication and/or other home solutions in the face of a health problem; they only seek professional care, be it the Basic Health Unit or the hospital when they identify the worsening of symptoms. The idea of prevention and/or self-care strategies are almost absent from the lines. In this direction, we highlight the importance of analyzing the singularities of the male population in each region, recognizing the reality of the services available in each context, the resources available for health care, as well as the need for qualification of health professionals to establish strategies aimed at the inclusion of the male public in the health scenario, being important to overcome the health care model, strongly present in the health network.
\end{abstract}

Keywords: Men's health, Primary health care, Masculinity, Health care (public health).

\section{Trayectorias de hombres que buscan atención médica: desafíos para la atención primaria en un contexto rural}

\section{Resumen:}

Estudio exploratorio cualitativo con el objetivo de comprender el camino de los hombres en busca de atención médica. Participaron en la encuesta 20 hombres, de entre 20 y 59 años de edad, residentes en la aldea de Laranjal, una comunidad rural del municipio de Arapiraca-AL. Entre ellos, 10 hombres habían utilizado el servicio de atención primaria de la salud en los últimos 12 meses y los otros 10 no habían utilizado este servicio en este período. La entrevista semiestructurada se utilizó como estrategia metodológica para construir la información. Para el análisis de los datos se utilizó el análisis de enunciación como marco teórico y analítico. Del análisis de los resultados se desprende que los hombres participantes en el estudio no tienen trayectorias (itinerarios) bien definidos, tal vez truncados, líneas frágiles para la conducción de sí mismos que se perfilan a medida que se presentan situaciones críticas de enfermedad; recurren con frecuencia a la automedicación y/u otras soluciones domiciliarias ante un problema de salud; sólo buscan atención profesional, ya sea en la Unidad Básica de Salud o en el hospital, cuando identifican el empeoramiento de los síntomas. La idea de prevención y/o estrategias de autocuidado están casi ausentes de las líneas. En este sentido, destacamos la importancia de analizar las singularidades de la población masculina en cada región, reconociendo la realidad de los servicios disponibles en cada contexto, los recursos disponibles para el cuidado de la salud, así como la necesidad de la calificación de los profesionales de la salud para establecer estrategias dirigidas a la inclusión del público masculino en el escenario de la salud, siendo importante la superación del modelo de cuidado de la salud, fuertemente presente en la red de salud. Palabras clave: Salud del hombre, Atención primaria de salud, Masculinidad, Atención a la salud. 


\section{INTRODUÇÃO}

Diversos estudos, principalmente epidemiológicos, tem apontado que os homens apresentam riscos diferenciados para diversas questões de saúde, demonstrando condições desfavoráveis em comparação às mulheres, do ponto de vista da morbimortalidade (FIGUEIREDO, 2008).

No Brasil, dados do Instituto Brasileiro de Geografia e Estatística no ano de 2010, revelavam que a expectativa de vida dos homens e mulheres era de, respectivamente, 69,73 e 77,32 anos (IBGE, 2011). A taxa de mortalidade na faixa etária de 20 a 59 anos, era 2,3 vezes maior entre os homens, do que entre as mulheres, chegando a ser quatro vezes maior na faixa etária de 20 a 39 anos.

A maior preocupação em relação a esses índices situa-se na exposição aos atos violentos, aos quais, se acrescentam outros problemas de saúde, como alcoolismo, tabagismo, neoplasias, hipertensão, diabetes e obesidade. É importante reconhecer que as formas como as masculinidades são produzidas e performadas em nossa sociedade, pela maioria dos homens, os conduz a práticas violentas como forma de resolução de conflitos, partindo da ideia popular de que "homem que é homem resolve as coisas na força" (MOURA; LIMA; URDANETA, 2012).

Sobre os homens incidem marcações simbólicas que os constituem como sujeitos fortes, inabaláveis e destemidos; características que não os permitem reconhecer-se como sujeitos de cuidado, nem mesmo para visibilizar suas próprias necessidades de saúde, inclusive no desenvolvimento de atitudes preventivas (QUIRINO; MEDRADO; LYRA, 2016).

Isto contribui para que, em situações de adoecimento, por exemplo, busquem auxílio médico predominantemente em caráter ambulatorial, em serviços de média e alta complexidade, ou mesmo hospitalares, retardando o cuidado e possibilitando o agravamento dos quadros de saúde (FIGUEIREDO; SCHRAIBER, 2011).

Alguns estudos destacam que, em geral, os homens buscam menos atendimento de saúde se comparados às mulheres, indicando várias razões para esse fenômeno (MOURA; LIMA; URDANETA, 2012), tanto no que tange aos modos de organização dos serviços e 
programações de saúde, quanto aos aspectos sociais e culturais, que interferem nas relações dos homens com sua própria saúde e com tais serviços.

O Governo Federal, buscando facilitar e ampliar o acesso dos homens brasileiros aos serviços de saúde, lançou em 2008, a Política Nacional de Atenção Integral à Saúde do Homem (PNAISH) (BRASIL, 2009) a qual, alinhando-se à Política Nacional de Atenção Básica (PNAB), estabeleceu a primazia da Estratégia Saúde da Família (ESF) como espaço fundamental para o desenvolvimento de ações de saúde para os homens, compreendendo que muitos problemas de saúde que os acometem poderiam ser evitados, ou ter seu agravamento reduzido, com atendimentos neste nível de atenção.

Contudo, se reconhece que as demandas em saúde da população masculina ainda são invisibilizadas pelos serviços locais de saúde, uma vez que existem dificuldades em desenvolver estratégias de trabalho que contemplem a população masculina, e por isto tais serviços ainda não são atrativos para os homens (MOREIRA; GOMES; RIBEIRO, 2016).

A utilização de serviços de saúde pela população é definida por diferentes fatores, dentre eles: a necessidade e disponibilidade de serviços de saúde, a propensão da população em utilizá-los e a facilidade de acesso. É possível ponderar uma interconexão entre esses fatores, modificando-os. A baixa frequência com que os homens buscam os cuidados preventivos também relaciona-se à pouca oferta desses procedimentos, sobretudo se comparamos com aqueles direcionados para mulheres na atenção básica (BASTOS et. al. 2016; MOREIRA; GOMES; RIBEIRO, 2016)

Sobre este aspecto é importante considerar ainda que nos processos saúde-doençaintervenção, a subjetividade e a objetividade do cuidado estão em mutação. Isto implica falar da possibilidade de mudanças nas formas como as prescrições formais são executadas, pois estas se metamorfoseiem nas práticas cotidianas, o que vai repercutir sobre os modos de operacionalização das políticas e programas de saúde no cotidiano dos serviços (FERIGATO; CARVALHO, 2011).

É o caso dos homens que habitam contextos rurais e localidades afastadas dos grandes centros urbanos, onde os recursos de saúde disponíveis são limitados, e a busca pela saúde envolve um traçado particular. No caso do estudo aqui desenvolvido, que teve por contexto 
um povoado da zona rural do município de Arapiraca, no estado de Alagoas, esta é uma questão fundamental.

Assumimos, dessa forma, que os homens residentes nesta localidade vivem de um modo bastante singular as questões simbólicas e objetivas que interferem nos seus percursos na busca por cuidados. Trata-se de um conjunto de planos e ações que se sucedem, mesclamse ou se sobrepõem para lidar com a promoção da saúde, a prevenção de doenças, a cura e a reabilitação.

Nessa direção, este artigo trata-se de um recorte de dissertação de mestrado em Saúde da Família, que buscou compreender as trajetórias percorridas por tais homens no processo saúde-doença-cuidado, desenhando seus caminhos e entendendo os fluxos assistenciais, para debater a efetividade da Estratégia Saúde da Família. Com isso, ponderamos também acerca dos obstáculos e dos elementos facilitadores do acesso dos homens aos serviços de saúde, em particular na Atenção Básica.

\section{MÉTODO}

Trata-se de uma pesquisa qualitativa, de caráter exploratório, e para a produção de informações em campo, foram realizadas entrevistas semiestruturadas com homens adultos, habitantes da comunidade rural selecionada para o estudo.

A pesquisa foi realizada em um povoado da zona rural do município de Arapiraca/AL, distante $13,9 \mathrm{~km}$ de sua região central. Possui boa acessibilidade, devido à proximidade com a rodovia AL-110, que atravessa toda sua extensão. A principal atividade econômica é a agricultura familiar. O povoado possui apenas uma escola de ensino fundamental, e não dispõe de outros equipamentos públicos, como centros de referência de assistência social, nem de lazer, como quadras esportivas, parques ou praças.

Quanto à rede de saúde local, o povoado abriga uma das quarenta unidades básicas de saúde (UBS) existentes em Arapiraca/AL, com funcionamento das $7 \mathrm{~h}$ às $16 \mathrm{~h}$, de segunda a sexta-feira. Esta UBS está situada às margens da AL-110, sendo de fácil acesso para a 
população, e conta com uma equipe da ESF, desde agosto de 2017, formada exclusivamente por mulheres.

Como referência nessa rede, o hospital de urgência do município, conveniado ao SUS, dista $14,8 \mathrm{~km}$. A cidade não possui Unidades de Pronto Atendimento (UPA), apesar de contar com um serviço ambulatorial de urgência com funcionamento de segunda a sexta-feira, das $7 \mathrm{~h}$ às $16 \mathrm{~h}$.

Foram entrevistados 20 homens na faixa etária de 20 a 59 anos (mesmo público-alvo da PNAISH), residentes nesta localidade. Dentre esses, 10 homens haviam buscado, recentemente, atendimento na UBS local, e os demais, à época da pesquisa, não haviam utilizado este serviço da atenção primária havia pelo menos 12 meses. A definição desses dois grupos teve o objetivo de ter acesso a diferentes experiências de relacionamento com o serviço local de saúde.

O roteiro das entrevistas, para os dois grupos de homens, foi composto por 07 questões, acerca do cuidado em saúde e acesso aos serviços de saúde. As entrevistas foram realizadas no mês de janeiro de 2019, com duração média de 28 minutos.

Os interlocutores foram convidados durante a realização de uma cerimônia religiosa na comunidade, momento em que foram realizados agendamentos para conversas posteriores. As entrevistas ocorreram nas casas de cada participante.

A opção pelo convite a esses homens durante a cerimônia religiosa se deu a partir de conversa em reunião administrativa da UBS, onde foram elencadas as estratégias que poderiam atrair o maior número de homens ao estudo. Todos os presentes foram unânimes em indicar a missa (na igreja católica), realizada aos domingos na comunidade, como o melhor local.

Após o convite aos interlocutores e o aceite de sua participação, a equipe de pesquisa procedeu ao deslocamento até as residências dos participantes, com apoio de Agentes Comunitários de Saúde (ACS). Todas as entrevistas foram realizadas por meio de duas pesquisadoras, sendo uma estudante do curso de graduação em Medicina da NN [eliminado para efeitos da revisão por pares], que realizava os questionamentos, sempre acompanhada da pesquisadora principal, que a auxiliava na condução do diálogo com os sujeitos. 
Quanto aos cuidados éticos, esta pesquisa foi aprovada pelo comitê de ética da Universidade Federal de Alagoas, sob o parecer nº 3.099.334, CAAE: 02833418.5.0000.5013, em conformidade com as regulamentações nacionais da ética em pesquisa.

As entrevistas foram audiogravadas e transcritas na íntegra para análise. Foi realizada uma análise temática dos discursos produzidos nas entrevistas, inspirado na análise de enunciação. Estratégia na qual a comunicação é interpretada como um processo, respeitando a lógica, a organização e as figuras de retórica produzidas durante as falas (MINAYO, 1999)

Desse forma, procedeu-se três etapas: 1) sistematização das informações, com a catalogação de todos os textos componentes do corpus analítico; 2) criação das categorias analíticas, por meio da leitura do material organizado na fase anterior; e, 3) síntese das informações, com destaque para os consensos e divergências que permeavam as falas dos homens participantes.

Foi utilizada os números 1 e 2 (grupo 1, aqueles que procuraram a UBS nos últimos 12 meses e o grupo 2, quem não utilizou esse serviço), seguida da primeira letra do nome para identificar a fala de cada participante.

Observando os princípios ético-políticos das pesquisas qualitativas em saúde, o estudo apresentou algumas limitações de âmbito metodológico. Aqui destacamos os dois aspectos principais. Os participantes do estudo foram da matriz religiosa com o maior número de seguidores na comunidade, assim, homens de outros credos religiosos não contribuíram na pesquisa.

A realização das entrevistas contou com a presença de profissionais da UBS de referência. Portanto, além dos aspectos jurídico-normativos das pesquisas com seres humanos, ocorreu o exercício ético do resguardo das relações de poder abusivas, considerando que não pode haver relações hierárquicas, respeitando, inclusive, o direito de não resposta dos entrevistados. 


\section{RESULTADOS E DISCUSSÃO}

No processo de análise das entrevistas, foram identificadas duas categorias temáticas principais: (A) Serviços e recursos de saúde acessados (UBS, Hospital, Pronto Atendimento e farmácias comerciais); e, (B) Os sujeitos do cuidado em saúde (profissionais da medicina, agentes comunitários de saúde e esposas) e as barreiras pessoais. Estas categorias serão exploradas ao longo desta sessão, esboçando a construção das trajetórias seguidas pelos homens na sua busca por cuidados à saúde.

\section{Serviços e recursos de saúde acessados}

Todos os homens entrevistados residem há pelo menos cinco anos na comunidade, o que demonstra já ter havido tempo para o reconhecimento do serviço de saúde local (UBS) e desenvolverem algum relacionamento com ele. O Quadro 1 sintetiza informações gerais dos 20 homens participantes do estudo, sinalizando aqueles que compareceram (ou não) ao serviço no último ano.

Pode-se observar que seis entrevistados são agricultores, e os demais possuem ocupações distintas (vigilantes, motorista, serviços gerais, ajudantes e beneficiários). Em geral, tratam-se de ocupações que podem ter flexibilidade de horário, possibilitando-os de adaptarem suas jornadas de trabalho ao período de funcionamento da UBS, de modo a frequentar consultas e outros tipos de atendimento quando necessário. 
Quadro 1 - Informações gerais dos homens participantes do estudo

\begin{tabular}{|c|c|c|c|}
\hline $\begin{array}{l}\text { Comparecimento à UBS } \\
\text { no último ano (2018) }\end{array}$ & Idade & Ocupação & $\begin{array}{c}\text { Tempo de residência } \\
\text { na comunidade (em } \\
\text { anos) }\end{array}$ \\
\hline Sim & 59 & Agricultor/Pecuarista & 20 \\
\hline Sim & 43 & Beneficiário & 34 \\
\hline Sim & 52 & Agricultor & 35 \\
\hline Sim & 54 & Vigilante & 5 \\
\hline Sim & 36 & $\begin{array}{l}\text { Trabalha em uma } \\
\text { distribuidora }\end{array}$ & 12 \\
\hline Sim & 39 & Vigilante & 39 \\
\hline Sim & 39 & Funcionário público & 39 \\
\hline Sim & 37 & Beneficiário & 37 \\
\hline Sim & 35 & Agricultor & 35 \\
\hline Sim & 45 & Agricultor & 25 \\
\hline Não & 57 & Agricultor & 41 \\
\hline Não & 40 & Serviços Gerais & 15 \\
\hline Não & 40 & Microempresário & 17 \\
\hline Não & 33 & Motorista & 22 \\
\hline Não & 34 & Auxiliar de Produção & 34 \\
\hline Não & 46 & Ajudante Geral & 10 \\
\hline Não & 56 & Agricultor & 46 \\
\hline Não & 28 & Autônomo & 6 \\
\hline Não & 26 & Serviços Gerais & 26 \\
\hline Não & 34 & Serviços Gerais & 18 \\
\hline
\end{tabular}

Fonte: Autores.

A questão do acesso, como atributo da ESF, foi tangenciada pelos homens nas entrevistas, apontando como serviço de primeiro contato, ou porta de entrada do sistema de saúde para estes. Em seus relatos, mencionam que a UBS é o recurso disponível quando se sentem adoecidos. Um deles chegou a ressaltar que sempre é atendido e de forma adequada. 
1A: Procuro o posto de saúde. É o meio que a gente tem aqui. (...) É, todo tempo que eu procuro o posto, sou atendido.

1E: Procuro primeiramente o posto.

1I: Quando eu vou pro 'laranjal'(UBS), sou atendido. Cheguei lá e fui atendido direito.

Para atuar como porta de entrada, a UBS deve ser acessível à população adscrita, eliminando-se barreiras financeiras, geográficas, temporais e culturais. Na experiência de alguns dos homens entrevistados, a facilidade para conseguir a consulta, o fato de terem sido bem tratados pela recepcionista e pelos profissionais de saúde estão diretamente relacionados com uma maior satisfação do serviço de saúde (BURILLE, 2012; BASTOS; FASOLO, 2013).

Figueiredo (2005) afirma que os homens possuem mais dificuldade de buscar os serviços de saúde da Atenção Primária, seja devido à espera pela assistência, seja pela identificação do espaço da UBS, como feminino, ao ser mais frequentado por mulheres (usuárias e profissionais), causando uma sensação de não pertencimento àquele local. Além disso, alguns profissionais de saúde não estão preparados para receber esses usuários em seu cotidiano e realizar um acolhimento eficaz, o que foi relatado por alguns entrevistados.

2I: Geralmente a gente sempre procura, mas a dificuldade no atendimento é que faz a gente procurar outros meios de cuidar da saúde.

1F: Na última vez que eu fui pra lá, eu cheguei lá 13:30 com a garganta inflamada, não podia nem engolir a saliva nem nada, aí tinha bastante gente lá e acho que ela (técnica de enfermagem) esqueceu e deu duas, três, quando foi umas quase quatro ai a médica para, aí foi quando ela veio cá e falou que 'olha a gente botar um termômetro e se passar dos 40 ou era 39, sei lá, se tiver com febre, nós atende, senão você vai pra casa e volta no outro dia', só que disse 'rapaz eu cheguei uma e meia e agora você vem falar isso?'. Não teve jeito não.

Situações como as narradas acima podem explicar, em parte, o distanciamento dos homens de tais serviços. Em contrapartida, estes usuários acessam prioritariamente os serviços de urgência e outros equipamentos de média complexidade (ambulatórios, hospitais, etc), por perceberem que em tais lugares podem ter respostas mais objetivas às suas situações de adoecimento, com atendimentos mais ágeis e realização de procedimentos imediatos (FIGUEIREDO, 2008). 
Nas entrevistas, os homens referiram realizar uma autoclassificação de seu estado de saúde, distinguindo entre as situações que supostamente indicariam a necessidade de buscar um serviço de saúde, daquelas que poderiam ser resolvidas por conta própria, por meio da automedicação ou outras formas domésticas de cuidado.

Reconhecemos que existe certa naturalização, na população em geral, em torno da automedicação, em que os sujeitos classificam o que sentem e deliberam a busca de um serviço de saúde ou, por conta própria, o consumo de medicamentos (VIEIRA et. al. 2013). Em nosso estudo, a automedicação foi observada tanto nas falas dos homens que buscaram o serviço, quanto daqueles que não buscaram, conforme os trechos destacados a seguir:

1F: Se for uma gripe, ou uma coisa assim é chazinho, mas se ver que é virose ou essas coisas que não resolve com remediozinho assim, aí corre lá (UBS) pra ver o que é.

1H: Às vezes é um dorzinha de cabeça, que a dor passa com um medicamento, aí quando não dá, dou um pulinho no posto.

2B: É assim, que se a pessoa sentir que é coisa pouca, compra um remédio por conta própria na farmácia. Eu acho que se a pessoa sentir dores fortes né, alguma dor forte, a pessoa tem que procurar ajuda ligeiro. Uma gripe a pessoa procura um xarope, toma e fica bom né, mas passado do prazo aí tem que ir atrás da ajuda.

Palodeto e Fisher (2018) afirmam que, quando enfermos, homens tendem a procurar, inicialmente, farmácias e pronto-socorro. Neste sentido, a automedicação é considerada um meio de manutenção da saúde, de prevenção de enfermidades, e de tratamento de afecções e sintomas percebidos, em que não há a prescrição, a orientação ou o acompanhamento de um profissional de saúde.

Dentre os medicamentos mais utilizados na automedicação, destacam-se os analgésicos e anti-inflamatórios, em decorrência da fácil aquisição, em que não é necessária receita médica, destinados principalmente para alívio da dor (PRADO et. al. 2016).

Observamos que os entrevistados se referem muitas vezes aos medicamentos utilizando termos diminutivos ("remedinho"), como um eufemismo a automedicação, relacionando-a como uma prática habitual e sem muita importância. Além disso, alguns dos medicamentos mais utilizados são por eles reconhecidos pelos seus nomes fantasias, e não 
pelos nomes dos princípios ativos, isto em razão do estímulo ao nome comercial amplamente difundida nas propagandas e no comércio em geral.

2D: Acho que o cara acha que é passageiro não vai, pode tomar um remedinho.

1H: Às vezes é um dorzinha de cabeça, que quando a dor passa com um 'Torsilax ${ }^{\oplus}$, aí quando não dá um pulinho no posto.

2C: Dor de dente, dor de cabeça, dor muscular né, os remédios hoje em dia qualquer remédio de dor passa. Isso resolve em casa.

2H: Comodismo. Toma um 'Histamin ${ }^{\oplus ’}$, resolve, aí pronto. Aí a gente, né, não vai procurar.

1I: O cara fica em casa mesmo, toma um remedinho, pra ver se fica melhor né.

Quanto ao conhecimento das atribuições ofertadas nos serviços da APS, observamos que boa parte dos entrevistados entende que, quando necessitarem de determinados tipos de cuidados mais complexos, devem procurar outros níveis de atenção na rede.

A perspectiva da rede, composta por serviços em distintos níveis de complexidade e de competências não deve ser esquecida, os usuários podem procurar qualquer nível de atenção quando necessitam de assistência, mas devem ser encaminhados ao nível mais adequado ao seu problema, seja agudo ou crônico, através da classificação de riscos em cada local.

A UBS no território oferta à essa população, serviços como imunizações, curativos, coleta de exames laboratoriais, dispensação de medicação, consultas com a médica de família e a enfermeira, e conta com o apoio de uma equipe do Núcleo Ampliado de Saúde da Família e atenção básica.

Observando que os homens apresentam baixa adesão às ações de promoção e prevenção, e que os mesmos acessam o sistema de saúde através da atenção especializada, estes devem ser orientados na busca correta ao serviço de saúde correspondente à sua necessidade. 
1C: Em primeiro lugar eu busco o posto de saúde, mas se acontecer de no posto de saúde não ter o recurso necessário, aí eu tenho que procurar o hospital, a unidade de emergência, por aí.

1A: Tem que ir no posto procurar o doutor que esteja lá, né, pra ele dar alguma certificação se precisa sair pra outro canto, né?

1G: Sempre procurei auxílio no posto, aí me passaram pra outros médicos, questão de coluna, aí foi com outros médicos no centro (centro de referência de especialidades).

Outro fator referido como interveniente na ida aos serviços é a dificuldade de atendimento para os homens inseridos do mercado de trabalho, visto que os horários dispostos na APS são pouco convenientes, competindo com os expedientes laborais e outros compromissos.

2D - "É bem dependendo assim né, porque nunca tá no horário que a pessoa pode ir né. Mas se for, com certeza é atendido".

Sobre este aspecto, o estudo de Gomes et. al. (2011) observou que as unidades básicas, em geral, são organizadas para o funcionamento em horários quase sempre incompatíveis com o "homem trabalhador", acoplado ao reconhecimento no mundo do trabalho de que apenas a mulher teria necessidades de uso regular dos serviços.

No entanto, as mulheres também têm ocupado diversos postos de trabalho e isto não as impede de buscar os serviços de saúde para se cuidar ou pelo menos não é tão frequente as mulheres usarem este argumento de incompatibilidade de horários entre o trabalho e o cuidado de si (FIGUERIREDO; SCHRAIBER, 2011; MOREIRA; GOMES; RIBEIRO, 2016).

Estudos também realizados com homens no contexto da atenção básica evidenciam que, mesmo quando desempregados, os homens continuam usando o argumento de que não procuram serviços de saúde porque as unidades de saúde, em geral, estão abertas apenas em horário comercial (FIGUERIREDO; SCHRAIBER, 2011).

Na pesquisa, vimos que essa questão não parece se constituir como fundamental, uma vez que, dentre os homens entrevistados, muitos apresentavam compromissos de trabalho flexíveis, e ainda assim não haviam comparecido ao serviço há pelo menos um ano.

Não é trabalho em si, ou especificamente o horário em que este acontece, que impede essa busca pelos homens, mas a forma como eles se relacionam com o trabalho, ou, mais 
precisamente, como a dimensão simbólica que o trabalho possui nas suas vidas se articula com o desenvolvimento (ou não) de práticas de cuidado.

Ademais, a ampliação do turno de funcionamento das UBS, visando melhorias no acesso e acolhimento dos homens, constitui grande desafio para os sistemas locais de saúde, pois esbarra na questão da segurança, devido à violência observada em alguns contextos.

Além dessas barreiras institucionais, tanto o acesso quanto a frequência nos serviços de saúde aparecem também relacionados ao fato de os homens não se reconhecerem como doentes ou se negarem a comparecer aos serviços, como afirmam Oliveira et al (2015). Nas falas de alguns entrevistados, aparecem o desinteresse e/ou desestímulo em relação ao (re)conhecimento das atividades prestadas pela UBS, e, mesmo, acabam assumindo sua responsabilidade em não acessá-la:

1G: "Fornece (acesso), só que o 'caba' (homem) não vai lá, difícil."

2E: "Rapaz, eu procuro assim, quando é necessário, negócio de injeção mesmo. Mas não por... é por falta de vontade mesmo de ir. O posto, ele fornece tudo certinho."

2G: "Eu acho que a gente relaxa um pouco, né, vai relaxando, vai ficando ali, achando que depois toma alguma coisa e acha que vai melhorar e não vai. Aí quando der fé, tá que não pode nem ir, é os outros quem leva. A maioria aqui é assim."

2H: "Sim (UBS fornece acesso). Apesar de eu nunca ter procurado, mas eu sei que oferece."

Em uma rápida reflexão, podemos compreender que há nestes trechos uma tendência destes homens em reduzir a (co)responsabilidade do serviço, e atribuir a si mesmos uma (ir)responsabilização pela sua situação de saúde. Compreendemos que os desafios no acesso à APS são inúmeros, necessitando de ações programáticas e estratégicas de saúde que dialoguem com o cotidiano dos homens, bem como que rompam com barreiras institucionais, pessoais e socioculturais, com vistas à inclusão da população masculina nos serviços de atenção primária à saúde. 


\section{Os Sujeitos do Cuidado em Saúde e as Barreiras Pessoais}

A segunda categoria analítica do estudo desvela como a busca de cuidados à saúde pelos homens, em geral, é mediada por outros sujeitos, a partir da qual se podem colocar alguns desafios postos à APS na oferta de uma atenção integral à população masculina.

No contexto da ESF, o Agente Comunitário de Saúde (ACS) tem um papel essencial, pois é ele quem faz a ligação entre a equipe de saúde e a população atendida, atuando como agente mediador e multiplicador (MOROSINI; FONSECA, 2018).

Na rotina do ACS, a atividade preponderante é a Visita Domiciliar (VD), que possibilita o acompanhamento in loco das condições de saúde das famílias de sua microárea e na busca ativa de situações específicas. Nas VD, os agentes cadastram os membros da família, realizam orientações diversas, informam sobre a dinâmica de funcionamento dos serviços, entre outras ações. As VD são a principal expressão da presença do ACS no território. Em nossas entrevistas, a menção à relação com as ACS do território pesquisado mostrou-se presente, tratando de sua atuação na aproximação entre o homem usuário e a unidade de saúde.

1G: É questão de ir no posto é mais quando a agente (ACS) aparece e diz "vá lá que tem uma consulta".

1H: De três em três meses eu vou lá pegar o remédio. Vou lá e mando a menina (ACS) fazer a receita e quando é com oito dias eu pego a receita.

Os ACS, além de outras atribuições, têm desenvolvido papel significativo no chamamento e na articulação da comunidade com os profissionais de saúde, sendo muitas vezes referenciados à facilitação do acesso a consultas, exames, medicamentos e outras ações. Muitas vezes, são eles que detectam as necessidades dos usuários e as levam ao conhecimento dos demais membros da equipe de saúde (MOROSINI; FONSECA, 2018).

Mesmo com a atuação dos ACS no território, os homens entrevistados tendem a relatar a ida ao hospital antes mesmo da busca da Atenção Básica, preterindo o serviço mais próximo à sua casa. A perspectiva hospitalocêntrica é percebida em diversas falas desses usuários.

A ESF é uma estratégia de reorientação do modelo médico-centrado, nela, o foco da atenção é direcionado à família de um determinado território social (MARTINS et. al. 2020). 
Propõe, ainda, uma mudança na organização do trabalho, que deve ser construído baseado em equipe, visando práticas mais resolutivas e integrais, tomando como eixo condutor o modelo de vigilância à saúde. Na fala dos entrevistados, observamos práticas discursivas voltadas ao hospital que precisam ser desmistificadas.

2A: Até hoje num fiquei doente pra não procurar né atendimento, geralmente tem que ir no hospital né. As vezes que eu adoeci fui pro Hospital.

2D: Sempre a gente vai pro Regional (Hospital de urgência do município).

2G: Aqui, tem que procurar (auxílio médico) logo é na cidade, né. Vai no hospital, né?

O uso dos serviços de saúde pelos homens direciona-se para a assistência a agravos e doenças, em que procuram por atendimentos, em geral, em situações de extrema emergência, em nível especializado ou de urgência (ARRUDA; BARRETO; MARCON, 2015). Estes, com suas crenças de invulnerabilidade, tendem a adiar ao máximo a busca por cuidados. Tal cenário é reflexo de modelos tradicionais de masculinidade e seus processos de socialização, os quais tendem a afastar os homens das preocupações com o autocuidado e, consequentemente, a busca dos serviços de saúde. Há, ainda, no ambiente familiar, uma marca cultural que não os estimulam ao cuidado, fazendo com que recorram aos serviços de saúde apenas diante de intercorrências graves.

Há uma exigência, socialmente construída e historicamente sustentada, de que o homem precisa ser forte, adiando tratamentos preventivos (MOROSINI; FONSECA, 2018; BURILLE et. al., 2018). Culturalmente, os homens são vistos como corajosos, invulneráveis e protetores, treinados (ou convencidos) para suportar suas dores (físicas ou emocionais) sem se preocuparem com a própria saúde.

1F:Quando me adula [insiste] muito é que eu vou pro posto, só quando não tem mais jeito aí é que eu vou, pro posto ou hospital.

2H: Ah, primeiro pergunto à mulher, alguma coisa, informação. Depois, se for último caso, a gente procura, né? Ir pra um hospital, qualquer consultório. 
Um dos entrevistados ainda relatou que questiona à sua esposa acerca de informações relativas à sua saúde antes de decidir qual serviço procurar. As esposas/companheiras acabam sendo grandes aliadas na busca de soluções de saúde destes usuários. Geralmente, elas os levam para os atendimentos, marcam suas consultas e cobram a realização de exames periódicos. Aparecem, desse modo, como referências importantes destes homens quando se sentem adoecidos, o que nos parece demonstrar a importância que as redes informais, representada pelo saber popular, doméstico e familiar, apresenta no suporte a situações conflituosas para estes homens.

Assim, outros componentes relacionados ao ato de cuidar, tais como as interações afetivas e as relações sociais, também precisam ser levadas em conta quando estes homens necessitam enfrentar questões de saúde. Além disso, as menções ao espaço familiar nos indicam também que tais pessoas de referência podem ser importantes e significativos parceiros para uma intervenção integral à saúde dos homens.

No estudo de Arruda, Barreto e Marcon (2015) as esposas fazem parte da rede de apoio masculina, tendo um papel importante no cuidado com a saúde, mais especificamente ajudando a lembrar do uso de medicamentos ou o dia de consultas.

Há que citar ainda, os homens que não procuram nenhum serviço da rede pública de saúde (UBS, centros de média complexidade ou hospitais) e preferem buscar médicos particulares realizando toda sua assistência através da Medicina Privada. Algumas empresas fornecem planos de saúde aos seus funcionários. Outros procuram planos de saúde fora da empresa e pagam mensalmente para terem cobertura de serviços ambulatoriais e hospitalares.

Três dos entrevistados relataram procurar esses serviços por terem condições de pagá-los. Um deles chegou a referir que a dificuldade no atendimento público é um dos motivos que o levam a procurar a assistência privada à saúde.

2C: Eu mesmo não procuro o posto, vou diretamente no médico particular. Nunca procuro o posto porque tenho condição de pagar, então procuro resolver logo pagando porque eu sei que eu vou lá e pago e resolve. 
2E: É porque assim, a unidade, na verdade, a gente paga o plano de saúde, né? Aí através do plano a gente faz pelo plano de saúde, né, a maioria das coisas, né?

2I: Geralmente a gente sempre procura, mas a dificuldade no atendimento é que faz a gente procurar outros meios de cuidar da saúde. Geralmente sempre é particular. A empresa que eu trabalho sempre manda periodicamente eu ir ao médico.

No município de Arapiraca, lócus da pesquisa, existe um sindicato de saúde e um centro médico integrado com consultas e exames a preços populares, os quais dispõem de uma rede mínima com especialistas focais e diversos tipos de exames, desde os laboratoriais aos de imagem, como ressonância magnética, o que facilita o acesso da população à medicina privatista.

Para Martins at. al. (2020), o modelo médico-assistencial privado valoriza a prática médica curativa, individual, assistencialista e especializada em detrimento da saúde pública. Observamos que a assistência privada não faz atividades de promoção e, mesmo em termos de prevenção, é bastante limitada.

Outra barreira, apresentada como justificativa à não busca pelos serviços da APS pelos homens, foi o medo.

2F: Às vezes é medo mesmo de médico, né? (...) É isso que eu falei, é medo mesmo.

2H: Eu sou doente, tenho alergia, era pra ter feito umas consultas sobre essa alergia e eu fico deixando pra lá, acho que é com medo, sei lá.

Seguindo esta direção, na pesquisa de Quirino, Medrado e Lyra (2016) alguns argumentos dos homens entrevistados se combinavam para justificar a sua falta de cuidados à própria saúde. Os homens atribuíam características a si mesmos para justificar atitudes de negligência, referindo explicações para a despreocupação do homem com a saúde e, ao mesmo tempo, para a não busca do atendimento profissional. Tais motivos acabam remetendo a sentimentos demonstrados pelos homens entrevistados em nosso estudo, e que os fazem adotar tal postura, tais como a vergonha, o medo e a timidez. 
Estes argumentos, apresentados pelos homens para camuflar seus sentimentos e ansiedades, reiteram a necessidade de mais estudos que considerem a população masculina como foco de problematização, em especial, para dialogar com homens que habitam contextos não urbanos, como a comunidade rural estudada, em que questões relacionadas ao acesso, acolhimento e disponibilidade de serviços de saúde são tangenciadas por modos de vida e construções socioculturais particulares, que acentuam atitudes e comportamentos considerados hegemônicos.

\section{CONSIDERAÇÕES FINAIS}

Neste artigo, a partir de diálogos com homens que habitam uma localidade rural no interior de Alagoas, pode-se compreender as diferentes formas como as práticas de cuidado à saúde vão se constituindo a partir de movimentos individuais e coletivos, e ao mesmo tempo, de que modo os serviços de saúde vão sendo acessados, ou ao menos, incluídos neste processo.

Observamos que os homens participantes do estudo não têm trajetórias (itinerários) bem definidas, talvez tracejados, linhas frágeis para a condução de si mesmos que se esboçam, à medida que situações críticas de adoecimento surgem em sua frente.

As soluções apresentadas dialogam com diferentes fatores pessoais (medo, timidez, mediação do cuidado pelas companheiras e agentes de saúde), socioculturais (modos de ser masculinos) e institucionais (disponibilidade de serviços de saúde, atuação dos agentes de saúde, horários de trabalho e funcionamento dos serviços), os quais se colocam ora como barreiras, ora como facilitadores do cuidado.

O grupo que frequentou o serviço local de saúde no último ano, o reconhece como um recurso à sua disposição, e sabem que quando se sentirem adoecidos, (acreditam que) podem acessá-lo. Por sua vez, aqueles que não frequentaram o serviço, ora recorrem ao hospital, ora ficam em casa e se automedicam.

Apesar disso, estes homens tem ciência da existência da UBS naquela localidade, apenas não a inserem em suas "frágeis" rotas de cuidado, seja por descuido, seja por 
considerarem outras soluções julgadas mais viáveis. Não ocorrendo uma adesão as ações ofertadas pela UBS.

Nesta direção, destacamos a importância de se analisar as singularidades da população masculina de cada região, reconhecendo a realidade dos serviços disponíveis, a necessidade de qualificação dos profissionais de saúde para serem estabelecidas estratégias voltadas à inclusão do público masculino, reconhecer que os homens também tecem estratégias de cuidado com a saúde, bem como a necessidade de superação do modelo assistencialcurativista, fortemente presente na rede de saúde.

\section{REFERÊNCIAS}

BASTOS, Gisele Alsina Nader; DUCA, Giovâni Firpo Del; HALLAL, Pedro Curi; SANTOS, Iná S. Utilização de serviços médicos no sistema público de saúde no Sul do Brasil. Rev. Saúde Pública, São Paulo, v. 45, n. 3, p. 475-484, June 2011. Available from <http://www.scielo.br/scielo.php?script=sci_arttext\&pid=S0034-89102011000300005\&lng=en\&nrm=iso>. Acesso em: 08 abr. 2020.

BASTOS, Gisele Alsina Nader; FASOLO, Luísa Rabeno. Fatores que influenciam a satisfação do paciente ambulatorial em uma população de baixa renda: um estudo de base populacional. Rev. bras. epidemiol., São Paulo, v. 16, n. 1, p. 114-124, Mar. 2013. Available from <http://www.scielo.br/scielo.php?script=sci_arttext\&pid=\$1415-790X2013000100114\&lng=en\&nrm=iso> Acesso em: 08 abr. 2020.

BRASIL. Ministério da Saúde. Secretaria de Atenção à Saúde. Departamento de Ações Programáticas e Estratégicas. Política Nacional de Atenção Integral à Saúde do Homem: Princípios e Diretrizes. Brasília (DF): Ministério da Saúde, 2009.

BURILLE, Andréia; GERHARDT, Tatiana Engel; LOPES, Marta Julia Marques; DANTAS, Guilherme Coelho. Subjetividades de homens rurais com problemas cardiovasculares: cuidado, ameaças e afirmações da masculinidade. Saude soc., São Paulo , v. 27, n. 2, p. 435-447, June 2018 . Available from <http://www.scielo.br/scielo.php?script=sci_arttext\&pid=S0104$12902018000200435 \& \operatorname{lng}=$ en\&nrm=iso>

. Acesso em: 08 abr. 2020.

BURILLE, Andréia. Itinerários Terapêuticos de Homens em Situação de Adoecimento Crônico: (des) Conexões com o Cuidado e Arranhaduras da Masculinidade. Dissertação (Mestrado em Enfermagem). Escola de Enfermagem, Universidade Federal do Rio Grande do Sul, Porto Alegre, 2012.

FERIGATO, Sabrina Helena; CARVALHO, Sérgio Resende. Pesquisa qualitativa, cartografia e saúde: conexões. Interface (Botucatu), Botucatu , v. 15, n. 38, p. 663-676, Sept. 2011 . Available from <http://www.scielo.br/scielo.php?script=sci_arttext\&pid=S1414-32832011000300004\&lng=en\&nrm=iso>

. Acesso em: 08 abr. 2020.

FIGUEIREDO, Wagner dos Santos. Masculinidades e Cuidado: diversidade e necessidades de saúde dos homens na atenção primária. Tese (Doutorado em Medicina Preventiva). Faculdade de Medicina, Universidade de São Paulo, São Paulo, 2008.

FIGUEIREDO, Wagner dos Santos; SCHRAIBER, Lilia Blima. Concepções de gênero de homens usuários e profissionais de saúde de serviços de atenção primária e os possíveis impactos na saúde da população masculina, São Paulo, Brasil. Ciênc. saúde coletiva, Rio de Janeiro, v. 16, supl. 1, p. 935-944, 2011.

FIGUEIREDO, Wagner. Assistência à saúde dos homens: um desafio para os serviços de atenção primária. Ciênc. saúde coletiva, Rio de Janeiro , v. 10, n. 1, p. 105-109, Mar. 2005. Available from <http://www.scielo.br/scielo.php?script=sci_arttext\&pid=S1413-81232005000100017\&lng=en\&nrm=iso>

. Acesso em: 08 abr. 2020. 
GOMES, Romeu; MOREIRA, Martha Cristina Nunes; NASCIMENTO, Elaine Ferreira; REBELLO, Lucia Emília Figueiredo de Sousa; COUTO, Márcia Thereza; SCHRAIBER, Lilia Blima. Os homens não vêm! Ausência e/ou invisibilidade masculina na atenção primária. Ciênc. saúde coletiva, Rio de Janeiro , v. 16, supl. 1, p. 983-992, 2011 . Available from $<$ http://www.scielo.br/scielo.php?script=sci_arttext\&pid=S1413-81232011000700030\&lng=en\&nrm=iso>

. Acesso em: 08 abr. 2020.

INSTITUTO BRASILEIRO DE GEOGRAFIA E ESTATÍSTICA. Tábua completa de mortalidade - 2010. Rio de Janeiro: 2011.

MARTINS, Elizabeth Rose Costa; MEDEIROS, Andressa da Silva; OLIVEIRA, Karoline Lacerda; FASSARELLA, Letícia Guimarães; MORAES, Paula Costa; SPÍNDOLA, Thelma. Vulnerabilidade de homens jovens e suas necessidades de saúde. Esc. Anna Nery, Rio de Janeiro , v. 24, n. 1, e20190203, 2020 . Available from <http://www.scielo.br/scielo.php?script=sci_arttext\&pid=S1414-81452020000100221\&lng=en\&nrm=iso>. Acesso em: 08 abr. 2020.

MINAYO, Maria C S. Pesquisa social: teoria, método e criatividade. 13. ed. Petrópolis: Vozes; 1999.

MOREIRA, Martha Cristina Nunes; GOMES, Romeu; RIBEIRO, Claudia Regina. E agora o homem vem?! Estratégias de atenção à saúde dos homens. Cad. Saúde Pública, Rio de Janeiro , v. 32, n. 4, e00060015, 2016 . Available from $<$ http://www.scielo.br/scielo.php?script=sci_arttext\&pid=S0102-311X2016000400710\&lng=en\&nrm=iso>. Acesso em: $08 \mathrm{abr}$. 2020.

MOROSINI, Márcia Valéria; FONSECA, Angélica Ferreira. Os agentes comunitários na Atenção Primária à Saúde no Brasil: inventário de conquistas e desafios. Saúde debate, Rio de Janeiro, v. 42, n. spe1, p. 261-274, Sept. 2018 . Available from $<$ http://www.scielo.br/scielo.php?script=sci_arttext\&pid=S0103-11042018000500261\&lng=en\&nrm=iso>. Acesso em: $08 \mathrm{abr}$. 2020.

MOURA, Erly Catarina de; LIMA, Aline Maria Peixoto; URDANETA, Margarita. Uso de indicadores para o monitoramento das ações de promoção e atenção da Política Nacional de Atenção Integral à Saúde do Homem (PNAISH). Ciênc. saúde coletiva, Rio de Janeiro , v. 17, n. 10, p. 2597-2606, Oct. 2012 . Available from <http://www.scielo.br/scielo.php?script=sci_arttext\&pid=S1413-81232012001000009\&lng=en\&nrm=iso>. Acesso em: 08 abr. 2020.

OLIVEIRA, Arruda Guilherme; BARRETO, Mayckel Silva, MARCON, Sonia Silva. Percepção de homens adultos sobre suas práticas preventivas e redes de apoio em saúde. Rev Rene, v. 16, n. 3, p. 363-73. 2015.

OLIVEIRA, Max Moura; DAHER, Donizete Vago; SILVA, Jorge Luiz Lima; ANDRADE, Silvânia Suely Caribé de Araújo. A saúde do homem em questão: busca por atendimento na atenção básica de saúde. Ciênc. saúde coletiva, Rio de Janeiro, v. 20, n. 1, p. 273-278, Jan. 2015 . Available from < http://www.scielo.br/scielo.php?script=sci_arttext\&pid=S141381232015000100273\&lng=en\&nrm=iso>. Acesso em: 08 abr. 2020.

PALODETO, Maria Fernanda Turbay; FISCHER, Marta Luciane. A representação da medicamentação sob a perspectiva da Bioética. Saude soc., São Paulo , v. 27, n. 1, p. 252-267, Jan. 2018 . Available from < http://www.scielo.br/scielo.php?script=sci_arttext\&pid=S0104-12902018000100252\&lng=en\&nrm=iso>. Acesso em: 08 abr. 2020.

PRADO, Maria Aparecida Medeiros Barros; FRANCISCO, Priscila Maria Stolses Bergamo; BASTOS, Tássia Fraga; BARROS, Marilisa Berti de Azevedo. Uso de medicamentos prescritos e automedicação em homens. Rev. bras. epidemiol., São Paulo , v. 19, n. 3, p. 594-608, Sept. 2016. Available from <http://www.scielo.br/scielo.php?script=sci_arttext\&pid=S1415790X2016000300594\&lng=en\&nrm=iso>. Acesso em: 08 abr. 2020.

QUIRINO, Túlio; MEDRADO, Benedito; LYRA, Jorge. Atenção em saúde aos homens no cotidiano da atenção básica: diálogos com usuários e profissionais. Athenea Digital. Revista de pensamiento e investigación social, [S.l.], v. 16, n. 3, p. 481-506, nov. 2016.

VIEIRA, Katiucia Letiele Duarte; GOMES, Vera Lúcia de Oliveira; BORBA, Marta Riegert; COSTA, César Francisco da Silva. Atendimento da população masculina em unidade básica saúde da família: motivos para a (não) procura. Esc. Anna Nery, Rio de Janeiro , v. 17, n. 1, p. 120-127, Mar. 2013 . Available from <http://www.scielo.br/scielo.php?script=sci_arttext\&pid=S1414-81452013000100017\&lng=en\&nrm=iso>. Acesso em: $08 \mathrm{abr}$. 2020. 